\title{
SOME RESULTS ON SUM AND PRODUCT OF RELATIVE GROWTH FACTORS OF COMPOSITE ENTIRE FUNCTIONS
}

\author{
Sanjib Kumar Datta, Banani Dutta And Nityagopal Biswas
}

Abstract. In this paper we study about the sum and product of relative $(p, q, t) L$-th type and relative $(p, q, t) L$-th lower type of an entire function with respect to another entire function in the light of a special type of non-decreasing, unbounded function $\Psi$.

Mathematics subject classification (2010): 30D35, 30D20.

$\Psi$.

Keywords and phrases: Entire function, growth, $(p, q, t) L$-th type, non decreasing unbounded function

\section{REFERENCES}

[1] R. P. Agarwal, S. K. Datta, T. Biswas And P. Sahoo, On the growth analysis of iterated entire functions, Advanced Studies in Contemporary Mathematics., 26, 1 (2016), 93-137.

[2] L. BERnAL, Orden relativ de crecimiento de funciones enteras, Collect Mth., 46, 1 (1917), 157-159.

[3] T. BISwAS, Some results relating to sum and product theorems of relative $(p, q, t) L$-th order and relative $(p, q, t) L$-th type of entire functions, Korean J. Math., 26, 2 (2018), 215-269.

[4] I. Chyzhy kov, J. HeittokAngas And J. RÄtTy Ä, Finiteness of $\varphi$-order of solutions of linear differential equations in the unit disc, J. Anal. Math., (2009), 109: 209-229, 10.1007/s11854-0090030-3.

[5] S. K. DATTA, T. BiswAS AND C. GHOSH, On relative $(p, q)$-th order based growth measure of entire functions, Filomat, 30, 7 (2016), 1723-1735.

[6] S. K. DATTA, T. BiswAS AND D. DutTA, Generalized relative type and generalized weak type of entire functions, Journal of Complex Analysis, (2016), Article ID 3468354, 11 pages.

[7] W. K. HAYMAn, Meromorphic functions, The Calendron Press, (1946).

[8] O. P. Juneja, G. P. Kapoor And S. K. BajPai, On the $(p, q)$-order and lower $(p, q)$-order of an entire function, J. Reine Angew. Math., 282 (1976), 53-67.

[9] O. P. JunEJA, G. P. KAPOOR AND S. K. BAJPAI, On the ( $p, q)$-type and lower ( $p, q)$-type of an entire function, J. Reine Angew. Math., 290 (1977), 180-190.

[10] L. M. Sanchez Ruiz, S. K. Datta, T. Biswas And G. K. Mandal, On the $(p, q)$-th relative order and oriented growth properties of entire functions, Abstr. Appl. Anal., (2014), Article ID 826137, 8 pages, http://dx.doi.org/10.1155/2014/826137.

[11] H. M. SRivastava, S. K. Datta, T. Biswas And D. DutTa, Sum and product theorems depending on the $(p, q)$-th order and $(p, q)$-th type of entire functions, Cogent Mathematics, (2015), $2: 1107951$, $1-22$.

[12] X. Shen, J. TU AND H. Y. XU, Complex oscillation of a second order linear differential equation with entire coefficients of $[p, q]-\varphi$ ' order, Advances in Difference Equations, (2014), 2014 : 200.

[13] D. Somasundaram And R. Thamizharasi, A note on the entire functions of L-bounded index and L-type, Indian J. Pure. Appl. Math., 19, 3 (1988), 284-293.

[14] G. VAliron, Lectures on the general theory of Integral functions, Chelsea Publishing Company, (1949). 